Article

\title{
The Power Paradox: Implicit and Explicit Power Motives, and the Importance Attached to Prosocial Organizational Goals in SMEs
}

\author{
Julie Hermans ${ }^{1,2, *(D)}$, Hendrik Slabbinck ${ }^{3}$ (D) , Johanna Vanderstraeten ${ }^{4}$, Jacqueline Brassey ${ }^{5}$, \\ Marcus Dejardin ${ }^{2,6}$ (D), Dendi Ramdani ${ }^{7}$ and Arjen van Witteloostuijn ${ }^{4,5,8}$ \\ 1 Louvain Research Institute in Management and Organizations, Université catholique de Louvain, 1348 \\ Louvain-la-Neuve, Belgium \\ 2 Centre for Research in Regional Economics and Economic Policy, Department of Economics, University of \\ Namur, 5000 Namur, Belgium; marcus.dejardin@unamur.be \\ 3 Department of Marketing, Ghent University, 9000 Gent, Belgium; Hendrik.Slabbinck@UGent.be \\ 4 Department of Management, University of Antwerp, 2000 Antwerpen, Belgium; \\ johanna.vanderstraeten@uantwerpen.be (J.V.); a.vanwitteloostuijn@uvt.nl (A.v.W.) \\ 5 Tilburg School of Economics and Management, Tilburg University, 5037 AB Tilburg, The Netherlands; \\ j.brassey@uvt.nl \\ 6 Institute for Multidisciplinary Research in Quantitative Modelling and Analysis, Université catholique de \\ Louvain, 1348 Louvain-la-Neuve, Belgium \\ 7 Office of Chief Economist, Bank Mandiri, Jakarta 12190, Indonesia; dendi.ramdani@bankmandiri.co.id \\ 8 Antwerp Management School, 2000 Antwerpen, Belgium \\ * Correspondence: julie.hermans@uclouvain.be; Tel.: +32-65-32-35-24
}

Received: 18 September 2017; Accepted: 25 October 2017; Published: 1 November 2017

\begin{abstract}
We examine the fundamental tension between explicit and implicit power motives; and their combined impact on the importance attached to prosocial organizational goals in small businesses (SMEs). We show that key decision-makers with a dominant implicit power motive attach more importance to the prosocial goals of job creation and taking care of the environment in their businesses. However, we reveal that this positive relationship is moderated by their explicit power motive. Once decision-makers in SMEs consciously seek for power, the positive relationship is neutralized. With these results, we highlight the conceptual and methodological differences between implicit and explicit power motives. We could obtain these results because we developed and validated an innovative implicit motive measure- the Shortened Pictorial Attitude Implicit Association Test (SPA-IAT). Contrary to the currently available implicit motive measures, the SPA-IAT is fast and easy to use and analyze, which makes this novel instrument well suited for research in business settings.

Keywords: explicit motives; implicit motives; power motive; Brief Implicit Association Test (BIAT); prosocial organizational behavior; job creation; environmental sustainability; small- and medium-size enterprise
\end{abstract}

\section{Introduction}

The world is engaged in a quest for a renewed form of capitalism [1,2]. Equating business with money-making is argued to be unsustainable, not only from an ethical perspective, but also from an economic viewpoint [3], as profit does not automatically imply societal wealth creation [4]. Furthermore, because shareholders are not the only legitimate stakeholders of an organization [5], profit is not the ultimate criterion for organizational success. In line with this thought, Porter and Kramer [1] argue that shared value creation is the new legitimate yardstick to measure organizational 
success. Shared value creation goes beyond the traditional economic goals and aims at improving societal quality of life.

Key decision-makers of small- and medium-sized enterprises (SMEs) have a critical responsibility in driving such societal wealth creation and renewal. As suggested by Schumpeter [6], entrepreneurs are social engineers [7]. They are (co-)responsible for advancing social development through the creation of a "new" and "better" society, notably by being innovative. Indeed, in particular SME key decision-makers have the unique opportunity to promote firm goals improving societal quality of life $[5,8]$.

One way of doing so is through prosocial organizational behavior. It involves all business activities that are intended to benefit others, such as helping, caring, cooperating or alleviating another's suffering $[9,10]$. The growing appreciation of SMEs in the economy [11] comes with an increased recognition of their social impact [12], such as the creation of jobs and the attention devoted to environmental protection [13]. As such, prosocial goals are gaining momentum in SMEs [14]. Stakeholders increasingly require proven positive impact on society from business [15], and most SMEs believe that they have social responsibilities [16]. In line with the growing institutional pressures for more voluntary corporate social responsibility (CSR) actions $[17,18]$ and the challenges SMEs face to remain competitive [14], SME key decision-makers incorporate prosocial goals within their business strategies [14].

Given the importance attributed to prosocial organizational behavior and the latter's relation to SME business strategies and performance [12], a next logical step is to unravel the factors influencing such behavior [10]. For example, it is well established that organizational factors, such as information availability and the time managers have to undertake discretionary business activities, drive prosocial behavior such as responsible "green" practices [19]. Especially in small businesses, where key decision-makers are able to directly shape the (economic and social) agenda of the firm [20], a key decision-maker's motivations are central to define the importance attached to different business goals.

In this paper, we argue that committing to prosocial goals requires specific and forceful personal drivers [3]. In the literature on business ethics and social entrepreneurship, tentative answers to understand the motivations for societal wealth creation point towards the potential role of an entrepreneurial spirit, the "joy of finding" [3], personal fulfillment, need for achievement, the desire to help society [21] or, the "joy of changing the world", as suggested by Nobel Prize Laureate Muhammad Yunus.

To examine personal drivers influencing prosocial organizational goal-setting, we build on McClelland's definition of power as having a physical, mental or emotional impact on other individuals, or groups of individuals. We suggest that key decision-makers who unconsciously enjoy influencing others and the world - and thus score high on McClelland's implicit power motive-attach more importance to their businesses' prosocial behavior. At the same time, decision-makers who explicitly and consciously seek more power-and thus score high on the explicit power motive-may refrain from engaging in prosocial behavior because of non-altruistic motivations. We examine this interesting puzzle, both theoretically and empirically, and seek to answer the following research question: What happens with SME key decision-makers' prosocial goal-setting when their implicit and explicit power motives are in conflict? By doing so, we add to the literature in three ways.

First, relying on insights from personality psychology, we reintroduce the construct of explicit and implicit motives in entrepreneurship, thus answering to a plea for further studies on individual drivers [22,23]. Second, we examine the conflicting roles of power, as defined by McClelland, as a driver of prosocial organizational goals. We show that implicit and explicit power motives are distinct constructs that have specific and combined effects on the attention devoted to prosocial goals. Third and finally, from a methodological point of view, we develop and validate the Shortened Pictorial Attitude Implicit Association Test (SPA-IAT), an innovative measure for implicit power motives. The SPA-IAT is an easy-to-use and reliable alternative to the time-consuming and/or subjective projective methods 
and content analyses that are traditionally used to assess implicit motives [24,25]. Before introducing our research design and presenting our evidence, we first turn to the underlying theoretical logic.

\section{Theoretical Framework}

Our theoretical argument is organized as follows. First, we suggest that SMEs represent a highly suitable setting to explore the impact of individual motives on organizational goal-setting. We highlight the role of (the motives of) the SMEs' key decision-maker in organizational prosocial goal-setting, compared to those of large firms. Then, we review the literature from social psychology and entrepreneurship on human motives and goal-setting to explain why and how both explicit and implicit motives in general, and McClelland's power motive specifically, are of interest for organizational goal setting and prosocial behavior. Finally, we introduce our model and develop our hypotheses.

\subsection{SMEs and Underlying Prosocial Mechanisms}

According to Nooteboom [26], SMEs' core features are the independence of the organization in terms of decision-making, and the overwhelming influence of the key decision-maker's personality on the firm's goals and strategies. The central role of an SME's key decision-maker has indeed been confirmed, notably by Miller and Toulouse [27], who show that "the relationships between personality and organizational characteristics were found to be by far the strongest in small firms" ([27], p. 1389). Indeed, in entrepreneurship literature, Rauch and Frese [28] claim that a key decision-maker, such as a firm owner, is the main source of action in smaller organizations. They discuss that small business owners have a stronger impact on company policy, company culture and the company's actions than owners of larger firms. As a result, Rauch and Frese [28] call for SME studies at the individual level to better understand organizational outcomes, such as goal-setting and performance.

Likewise, the literature on social psychology and goal-setting suggests that the thoughts and desires of key decision-makers tend to affect an SME more directly than a larger organization [29]. In addition, the specificities of small businesses have been stressed in sustainable entrepreneurship studies. In small businesses, key decision-makers directly shape the prosocial agenda of their firm [20]. Indeed, by sharing their values and transcending them throughout the firm, small business key decision-makers can develop a more authentic and effective approach to CSR [30], allowing small businesses to provide an answer to growing institutional pressures for deliberate CSR actions [18].

\subsection{Human Motives and Organizational Goal-Setting}

An important boundary condition in organizational prosocial goal-setting is the key decision-maker's motivation to commit to prosocial goals [31]. Given that this boundary condition is central to this paper, we review the literature on human motives in the entrepreneurship and goal-setting literature in three steps (see Table 1). First, we retrace the research trajectories of McClelland's motives in entrepreneurship literature, from its emergence in the 1980s to its-undue, as we will argue-demise. By doing so, we highlight a critical aspect of McClelland's theory that has been largely neglected in the entrepreneurship literature: The distinction between implicit and explicit motives. We then turn to more recent developments in personality and social psychology regarding the channels through which both explicit and implicit motives influence goal-setting, with specific and combined effects. Finally, we focus on the core issue of the current study: The role of power as a critical motive for influencing the world around us, notably inside SMEs where power-motivated key decision-makers can influence the importance attached to sustainability goals. 
Table 1. Key insights on human motives and organizational goal-setting.

\begin{tabular}{|c|c|}
\hline $\begin{array}{l}\text { Motives in entrepreneurship studies: } \\
\text { McClelland's undue demise }\end{array}$ & $\begin{array}{l}\text {-Who is the entrepreneur" is not the right question: Researchers } \\
\text { should look at what entrepreneurs do, not who they are [32] } \\
\text { Entrepreneurial action is influenced by self-regulation } \\
\text { mechanisms, where motives-especially the achievement } \\
\text { motive-might play a role [33] } \\
\text { Entrepreneurship research neglects the difference between } \\
\text { explicit and implicit motives [34], missing out on their specific } \\
\text { and combined effects on entrepreneurial action }\end{array}$ \\
\hline Dual motives and goal-setting & $\begin{array}{l}\text { - Explicit and implicit motives operate differently, notably in } \\
\text { terms of their influence on goal-setting }[35,36] \\
\text { Implicit motives "push" individuals toward actions that they } \\
\text { enjoy; explicit motives "pull" individuals toward actions that } \\
\text { they want [37] } \\
\text { Implicit and explicit motives might have adverse effects on the } \\
\text { same goal: Individuals may be pushed toward but pulled away } \\
\text { from the same goal, or vice versa [38] }\end{array}$ \\
\hline $\begin{array}{l}\text { Dual power motives and prosocial goal } \\
\text { setting in SMEs }\end{array}$ & $\begin{array}{l}\text { - The explicit achievement motive is a robust determinant of } \\
\text { prosocial organizational behavior [21] } \\
\text { - The implicit achievement motive is a less relevant determinant } \\
\text { of prosocial organizational behavior: Instead, implicit power is } \\
\text { the great motivator [39] }\end{array}$ \\
\hline
\end{tabular}

\subsubsection{McClelland's Legacy in Entrepreneurship Studies}

The study of motives in entrepreneurship started with the work of McClelland [40,41]. McClelland suggested a theory of human motivation that considers three key motives: The achievement motive, the power motive, and the affiliation motive. People with a dominant achievement motive typically get most satisfaction from mastering complicated tasks, but are dissatisfied when they are unable to master such tasks on their own [41]. Quite differently, people who are predominantly motivated by affiliation love to create, maintain, and restore social relationships. They experience unpleasant feelings when others signal rejection or hostility and they tend to avoid interpersonal conflicts [42], instead of solving them. Finally, individuals with a dominant power motive prefer to influence, teach or encourage others. They obtain most satisfaction from exerting social, physical or emotional impact on others or on the world at large, and experience social defeats as aversive [43]. Particularly, the achievement motive [44] was expected to explain performance differences between entrepreneurs and non-entrepreneurs [33]. However, inconclusive results [45] led to the conclusion that trait-based research, including human motives, is a dead-end strategy in entrepreneurship [32]. It was argued that we should look at what entrepreneurs do, not who they are [32].

In the present study, we argue that this claim is too one-sided. In line with Frese and Gielnik [46] and Stewart and Roth [44], we emphasize that human motives may very well explain variability between entrepreneurs and non-entrepreneurs, as well as among entrepreneurs. Indeed, Carsrud and Brännback [47] explain that both entrepreneurs and non-entrepreneurs might be driven by similar incentives. In line with this, we argue that it is a matter of understanding how motives can influence individuals, which motives make a difference in the entrepreneurial process [33], and which motives explain organizational outcome differences such as goal-setting. Even though managers and founders might have different motives [44], it is the underlying self-regulation mechanisms that are of interest here. In this paper, we thus argue to reopen the study on human motives in entrepreneurship and small business research. To do so, we only focus on SMEs and their key decision-makers, given the proven difference in personality impact on organizational goal-setting in SMEs vs. large firms [27].

On top of this, we argue that both explicit and implicit motives should be taken into account. Prior work overlooked the difference between implicit and explicit motives [48]. Collins et al. [33], for instance, rightly argue that latency-based instruments and questionnaires grasp different facets 
of motives, but suggest that they measure the same underlying constructs. Hence, they suggest that questionnaires are the best alternative, being easier to administer and being more accurate ([33], p. 112). More recently, Schuh et al. [49] provide the same argument when selecting questionnaires over so-called Thematic Apperception Test (TAT) instruments. In contrast, as said, recent work in personality and social psychology convincingly shows that explicit and implicit motives are two distinct concepts, implying that one approach should not be preferred over the other $[48,50]$. To examine this further, we turn to the distinction between explicit and implicit motives, as well as their specific impact on goal-setting, in the next section.

\subsubsection{Implicit and Explicit Motives, and Their Impact on Goal-Setting}

Starting with McClelland et al. [51], and supported by more recent work [52], personality psychology analytically distinguishes between two different motive systems [37]: (a) the implicit system that works at the unconscious level and through intrinsic motivation; and (b) the explicit system that operates under conscious awareness and via extrinsic control. A central proposition of this dual motive theory is that implicit and explicit motives relate to different aspects of the person, and that their activation is largely independent [51]. Using Berlew's push-pull metaphor, Kehr [37] suggests that implicit motives "push" individuals toward actions that they enjoy, while explicit motives "pull" them toward actions that they want.

According to Locke and Latham [35], conscious and explicit motives are more closely related to goal-setting than unconscious and implicit ones-i.e., primarily explicit motives affect goals (and performance), and they do so regardless of the subconscious. For this, they build on Bandura [53], who argues that individuals only extract from the subconscious what is in line with their explicit motives. In so doing, people control their own lives through conscious thinking. This is consistent with Brunstein et al. [36], who suggest that explicit motives are more closely related to goal development than their implicit counterparts, because goal development requires conscious thinking and planning [54]. In contrast, other researchers argue that implicit motives do have an impact on goal-setting through self-regulation [55]. If a goal turns out to be congruent with a person's implicit motives, satisfaction and subsequent goal reinforcement are the result [56]. The reverse happens when goals are not congruent with a person's implicit motives. In other words, people are able to update their goals through self-regulation after experiencing rewarding or aversive intrinsic cues [55].

\subsubsection{Motives and Prosocial Organizational Behavior}

To date, researchers in entrepreneurship and management mainly focused on the achievement motive [33,44,50], and more specifically its explicit counterpart. Stewart and Roth [44], for instance, convincingly show that individuals scoring higher on the explicit achievement motive have a higher proclivity to choose an entrepreneurial career. In the social entrepreneurship domain, too, the explicit achievement motive receives far more attention than the affiliation and power motives. For example, Ruskin et al. [21] identified the (explicit) achievement motive as a key motive in a study about social entrepreneurs' prosocial value creation.

Although we do recognize the importance of the explicit motives for entrepreneurship studies in general and prosocial behavior in particular, we also argue that their implicit counterparts are equally important for entrepreneurship and small business research [52]. According to traditional as well as more recent work on human motives, individuals with a dominant implicit achievement motive might not be successful in jobs that require social skills, such as managing an organization. Indeed, they are keen to function in an autonomous manner, and they prefer meeting a challenge on their own [41], making it hard for them to delegate [39]. This explains why the explicit achievement motive has been identified as a robust driver of entrepreneurial actions [33], whereas its implicit counterpart fails to provide consistent results [48]. What is more, McClelland and Burnham [39] argue that those scoring high on the power motive might be better suited to manage organizations: Power-motivated individuals are not afraid of conflicts, easily delegate tasks to their team members, and quickly 
overcome setbacks. As a result, their units expand faster, and their units are characterized by a better morale, compared to units led by managers with dominant achievement or affiliation motives.

On top of the relevance of studying the power motive in relation to business settings, human motivation research hints that a dominant power motive may foster prosocial and altruistic behavior [57], a statement yet to be tested empirically. Power-motivated people tend to employ behavioral strategies in a socially accepted, and not in a self-serving, personalized way [58]. By contrast, personalized power strategies are antisocial, profligate and impulsive in nature, and provoke aggressive and uncooperative reactions in others. As such, they limit the possibilities to have a long-lasting positive influence on others [58]. This is at odds with the goals power-motivated people enjoy. Moreover, power-motivated people are seen as persuasive and competent, and they tend to engage more frequently in many forms of generativity: They help other people to flourish, achieve, and be happy [59]. In addition, implicit power is significantly and positively related to employment growth [60].

To sum up, because: (1) studying the power motive in relation to business settings involving interactions with stakeholders is highly relevant; (2) the word prosocial "covers a broad range of actions intended to benefit one or more people other than oneself" ([61], p. 463); and (3) power-motivated people want to impact others, we argue that this motive is likely to be the most relevant one in relation to prosocial organizational behavior. In what follows, we first address the direct relationships between implicit and explicit power, on the one hand, and prosocial organizational behavior, on the other hand. We then turn our attention to the (in)congruence effects of implicit and explicit power motives.

\subsection{Model}

\subsubsection{The Positive Role of the Implicit Power Motive}

The implicit power motive is defined as the "capacity to derive pleasure from having physical, mental or emotional impact on other individuals or groups of individuals and, conversely, to experience the impact of others on oneself as aversive (Veroff and Veroff, 1972; Winter, 1973; Schultheiss et al., 2005b)" ([62], p. 606). People scoring relatively high on the implicit power motive enjoy having an emotional, physical and/or social impact on others, as well as on the world in general. Because implicit motives operate at the unconscious level through intrinsic motivation [37], the implicit power motive is aroused by factors "intrinsic" to the activity [63]. These factors are also referred to as "task incentives" by McClelland et al. [51]. People with a dominant implicit power motive, relative to affiliation and achievement, devote more time, energy, and attention to tasks that intrinsically provide opportunities to positively impact others or the world, such as teaching [64] and politics [43]. Consequently, with the right conditions in place, implicit power may foster socialized and prosocial, rather than self-serving and personalized strategies [58].

This claim is supported by recent work showing that power is significantly and positively related to employment growth [60]. Likewise, McClelland and Boyatzis [65] reveal that employees with a dominant implicit power motive, relative to affiliation, flourish in top-level positions, where they can influence their organization's trajectory. To maintain these top-level positions, they employ socially acceptable strategies that allow them to have a long-lasting impact on their co-workers, rather than resorting to directly aggressive and coercive behaviors that are likely to backfire [58]. As a result of this, a manager's implicit power correlates positively with team performance satisfaction and employee satisfaction with their management [66], and predicts managerial performance in high-level positions [65].

Recently, the role of the implicit power motive has been discussed in the context of prosocial motivations and behaviors. Magee and Langner [67], for example, show that implicit power drives prosocial decision-making-i.e., the power to promote collective welfare. Likewise, Baumann et al. [56] report that the implicit power motive fosters prosocial behavior, certainly in public settings and when long-term cooperation is required. In the context of the current paper, we argue that prosocial organizational behavior is about developing and ensuring collective benefits through the SME's activity, 
such as job creation and taking care of the environment (see below). Such behaviors are to the benefit of others and the world, and the corresponding actions typically intrinsically reward those scoring high on implicit power. Given this argument, we claim that the implicit power motive is an important driver of a key decision maker's attention for and importance attached to prosocial goals in SMEs.

Hypothesis 1 (H1). SMEs' key decision-makers with a dominant implicit power motive attach more importance to their SME's prosocial goals than do their counterparts motivated differently.

\subsubsection{The Negative Role of the Explicit Power Motive}

In contrast to implicit motives, explicit motives arise from extrinsic cues [37,68], also referred to as social incentives [51], such as social recognition. Hence, explicit motives are strongly influenced by social demands and normative pressures, independently from the intrinsic enjoyment of the task. An individual high on explicit power looks for positions and engages in activities that are viewed as prestigious and influential, and avoids positions and activities that damage her/his reputation. As a consequence, literature also reveals another face of power: Evidence suggests that power is also associated with self-interest and personal benefits, rather than with prosocial behavior [69]. For example, Maner and Mead [70] show that power-motivated leaders tend to prioritize their own interests over group goals.

Indeed, people with higher explicit power scores prefer self-beneficial opportunities (learn effective techniques of persuasion) above other-beneficial opportunities (learn coaching techniques to help others). Moreover, they opt for economic gains (profit maximization) instead of prosocial goals (communal well-being) [71]. Likewise, Schultz et al. [72] find a negative correlation between the explicit power motive and environmental concerns. In a similar vein, evidence portrays a negative relation between self-enhancement (that is, a focus on personal gains, such as personal prestige) and attitudes regarding communal welfare, including job creation [73]. This is in line with Boer and Fisher's meta-analysis [74], who find a positive link between social attitudes related to care and fairness, and self-transcendence values. Self-transcendence is the opposite of self-enhancement and encompasses a focus on the wellbeing of others. Further evidence suggests a negative correlation between explicit power and altruism [75]. People high on explicit power put their own interests as more important than those of others [76], implying that self-interest is promoted [77]. Self-interested behavior means that actions benefit the self, and-importantly—may harm the common good [78].

A plausible reason for the negative relation between explicit power and altruistic behavior is that prosocial behavior is extra costly for people who score high on explicit power. Signaling theory shows that individuals may use costly signals to transfer information about themselves to convince others [79]. Signals that do not fit with an individual's self-image are costly for the transmitter. (S)he does not possess the quality inherent to the signal, which makes such signaling very costly. As a result, signaling theory argues that it is very unlikely that those not possessing a quality will signal that quality. Altruism and prosocial acts can serve as such a costly signal [80]. Given that individuals scoring high on explicit power are not altruistic in nature [75], we argue that prosocial behavior is very unlikely in such cases.

Hypothesis 2 (H2). SME's key decision-makers scoring high on the explicit power motive attach less importance to their SME's prosocial goals than do their counterparts motivated differently.

\subsubsection{The Power Paradox}

The contrasting examples from literature about the impact of the implicit and explicit power motives on prosocial behavior demonstrate that we face an interesting paradox: How do these contrasting power motives interact and foster (or refrain) socialized (that is, prosocial) behavior [67]? We argue that the implicit power motive acts as a driver of prosocial behavior, while explicit power is 
negatively correlated with altruism [75] and the importance attached to prosocial goals. The question rises what happens when decision-makers are "pushed" toward prosocial goals by their implicit power motives, but "pulled" away from such aims by their explicit power motives.

While research in social psychology provides evidence that explicit and implicit motive systems develop independently, their interactions are still rarely investigated, especially in organizational settings. A notable exception is Kehr [37], who argues that implicit motives can influence behavior provided that two conditions are met: (1) the presence of unconscious and intrinsic signals related to implicit motives (in our case, SMEs' key decision-makers enjoying dealing with prosocial goals); and (2) the absence of competing conscious dispositions (in our case, SMEs' key decision-makers scoring high on the explicit power motive). When a conscious disposition triggers conflicting behavior, Kehr [37] expects the neutralization of the implicit impulse. More recently, Trapp and Kehr [38] report empirical evidence supporting such an interaction between implicit and explicit motives, showing that the positive impact of implicit power during negotiation processes can be neutralized by a competing explicit affiliation motive.

Relying on interaction models of implicit and explicit processes [51,81], we thus argue that a conscious disposition acts as a "gatekeeper", channeling implicit impulses. Because people scoring high on explicit power are non-altruistic, and rather focus on self-interests, we expect that their conflicting explicit power disposition neutralizes the positive effect of a dominant implicit power motive on the importance attached to prosocial organizational goals. Thus, we expect that in relation to prosocial goals, SMEs' key decision-makers will only enact upon their implicit power motive in the absence of a strong explicit power motive.

Hypothesis 3 (H3). SME's key decision-makers with a dominant implicit power motive attach more importance to their SME's prosocial goals than do their counterparts motivated differently, but only if their explicit power motive is low.

\section{Materials and Methods}

\subsection{Context}

We collected data through two online surveys in Belgium, as well as a series of workshops on entrepreneurial motives in Antwerp and Namur. The first survey was administered from November to December 2012 and the second one took place in May 2013. The workshops were organized in the summer of 2013. From the 2748 people who completed the first-wave survey, 220 registered online for the workshops and filled out the second survey in May. Of these 220, 108 eventually attended the workshops during the summer. The workshops took place both in the Southern (French-speaking Brussels and Wallonia) and the Northern (Dutch-speaking Brussels and Flanders) part of Belgium. Hence, the final sample is composed of 108 key decision-makers of Belgian businesses: 37 self-employed without employees, and 71 executives of small businesses with employees. All respondents had to identify themselves as key decision-makers of their business to participate in the study.

To avoid common-method variance, we carefully selected data from all three databases: The two surveys and the workshops. The dependent variables (job creation and taking care of the environment) as well as the control variables (firm size, sector, culture, ownership, gender, age and education level) were collected during the 2012 survey. Data about explicit motives were gathered online during the second survey when participants registered for the workshops. Implicit motives were measured during the workshops. The workshops were organized as follows: After a short introduction, the participants were led to a computer room, where their implicit motives were assessed. After the measurement exercise, the workshop continued with a lecture and discussion about human motivation, the interactions between (explicit and implicit) motives and entrepreneurial actions, and strategies to translate insights of the workshop into real business practices. 
To further address concerns with common-method variance in this study, we entered the items of the control, independent, moderator and dependent variable into one factor analysis as proposed by Podsakoff and Organ [82]. Seven factors with eigenvalues larger than 1 were extracted. This accounts for $71.86 \%$ of the variance. The first and second factor account for $17.02 \%$ and $11.41 \%$ of the variance, respectively. Since no common-method factor and no single factor emerged, we can safely conclude that common-method variance is not a significant issue in the current study. Common-method bias is even more unlikely given: (a) the inclusion of an implicit measure, which is (b) interacted with a survey counterpart.

\subsection{Measures}

\subsubsection{Explicit Power Motive}

Given that explicit motives are conscious, people can self-attribute underlying reasons to their actions [51]. As a result, explicit motives can easily be measured via self-reports in the form of questionnaires [52]. We used the achievement, affiliation and dominance (that is, power) subscales of the Personality Research Form [83] for the assessment of explicit motives, which is a self-report questionnaire that is frequently used to assess explicit motives [52]. Each subscale consists of 16 statements, and participants have to indicate to what extent each statement fits their self-perception on a five-point Likert scale ranging from $1=$ "Does not fit at all" to $5=$ "Fits very well". Sample items of the subscales are: (power) "The ability to be a leader is very important to me"; (affiliation) "I try to be in the company of friends as much as possible"; and (achievement) "I will not be satisfied until I am the best in my field of work". After recoding the reversed items, explicit motive scores were calculated by averaging the scores of all items associated with each subscale. Internal consistencies were good to excellent (Achievement: $\alpha=0.80$; Affiliation: $\alpha=0.87$; Power: $\alpha=0.89$ ).

\subsubsection{Implicit Power Motive}

Since implicit motives operate outside a person's awareness and (most) people lack introspective understanding of their implicit system [84], indirect measurement methods are needed [40]. Until recently, only projective methods such as the Thematic Apperception Test (TAT) and the Picture-Story Exercise (PSE) were available to assess implicit motives. The TAT and PSE are projective tests that present participants with a series of pictures that call upon the participants' implicit motives. The participant is asked to spontaneously develop a story for each picture. The assumption is that the participant projects her or his own needs into the story, so that the stories can be analyzed and interpreted to uncover each participant's underlying implicit motives. Even though recent work confirms the good psychometric qualities of PSE and related techniques [52], many researchers remain highly skeptical toward these so-called "subjective" techniques. Consequently, when new, yet "objective" indirect measures were developed in the 1990s, offering an alternative method, many researchers abandoned the subjective projective techniques in favor of the new objective techniques [50]. Regarding these objective methods, the Implicit Association Test (IAT) [84] is most interesting in the context of this research: It is by far the most popular "new" implicit measure, and has already been used to assess implicit power motives [25,71].

The IAT is a computerized response latency task that is assumed to measure the relative strengths of associations amongst two pairs of contrasted concepts (for example, "positive-negative" and "sunshine-rain"). Different variants of the IAT have been developed [85], and specific versions have been developed to measure implicit motives as conceptualized by McClelland $[24,25,71,86]$. Most interesting in this perspective is the Pictorial Attitude IAT (PA-IAT). Similar to the PSE and TAT and in line with implicit motive theory, the PA-IAT employs pictorial stimuli to arouse implicit motives and assess affective responses.

In a series of studies, Slabbinck et al. [24,25] provide compelling evidence regarding the validity of the PA-IAT. First, the PA-IAT psychometrically outperforms other implicit motive IATs that either 
employ verbal stimuli to represent motive imaginary or normative attributes (for example, "good" vs. "bad"). Second, the PA-IAT correlates significantly with the PSE, and is not related to explicit motive measures such as those measured through the PRF. Third, the PA-IAT predicts spontaneous behavior over and above traditional motive measures. In sum, the PA-IAT is a valid measure of implicit motives that can serve as a powerful alternative to the PSE. However, the IAT can be quite exhausting for respondents, too, thereby producing quick decline of quality when multiple motives are measured at once [85]. A possible solution is the development of a Brief IAT (or BIAT), a derivative of the IAT with similar characteristics, but with a shortened and simplified administration format [87].

In the current study, we assessed implicit motives with a variant of such a Brief IAT method: The so-called Shortened Pictorial Attitude Implicit Association Test, or SPA-IAT. The SPA-IAT is the brief version of the pictorial IAT developed by Slabbinck et al. [24]. Besides its shortened administration time, the BIAT is also one of the most reliable and valid latency-based measures available. Of the seven implicit measures compared by Bar-Anan and Nosek [85], the IAT and the BIAT show the best psychometric qualities, consistently across topics and evaluation criteria. Hence, the BIAT is a powerful alternative to the effort-consuming PSE and content analysis. In addition, the BIAT is less prone to manipulations than projective methods [88] when stories are written under the conscious supervision of the respondent. Another strength of the BIAT is the test-retest reliability, which is relatively high in comparison with other implicit instruments [85].

We constructed a SPA-IAT with seven blocks to measure implicit power, implicit affiliation, and implicit achievement. In the current paper, we focus on the results for implicit power, given our theory. The other motives are included here as well, because of the relative nature of the SPA-IAT (see below). An overview of the composition of our SPA-IAT procedure is presented in Table 2. 
Table 2. Structure of the SPA-IAT and construction of the SPA-IAT scores.

\begin{tabular}{|c|c|c|c|c|c|c|}
\hline & Label & Label & \multicolumn{4}{|c|}{ Stimuli Representing the ... } \\
\hline & Focal concept & Focal attribute & $\begin{array}{l}\text { Focal concept: } \\
\text { Pictures }\end{array}$ & $\begin{array}{c}\text { Focal attributes: } \\
\text { words }\end{array}$ & $\begin{array}{c}\text { Non-focal concept: } \\
\text { Pictures }\end{array}$ & $\begin{array}{c}\text { Non-focal attributes: } \\
\text { words }\end{array}$ \\
\hline Practice block & - & Attractive & - & & & \\
\hline Critical block 1 & Affiliation & Attractive & affiliation & & power & \\
\hline Critical block 2 & Affiliation & Attractive & affiliation & & achievement & \\
\hline Critical block 3 & Power & Attractive & power & $\begin{array}{l}\text { nice, friendly, } \\
\text { pleasant lovely }\end{array}$ & affiliation & $\begin{array}{l}\text { creepy, nasty, } \\
\text { annoving, undesired }\end{array}$ \\
\hline Critical block 4 & Power & Attractive & power & & achievement & \\
\hline Critical block 5 & Success & Attractive & achievement & & affiliation & \\
\hline Critical block 6 & Success & Attractive & achievement & & power & \\
\hline \multicolumn{7}{|c|}{ Calculation of Relative SPA-IAT measures } \\
\hline \multicolumn{7}{|c|}{ SPA-IAT $_{\text {pow-ach }}$ : performance on critical block 4 versus performance on critical block 6} \\
\hline \multicolumn{7}{|c|}{ SPA-IAT $_{\text {pow-aff: }}$ performance on critical block 3 versus performance on critical block 1} \\
\hline \multicolumn{7}{|c|}{ SPA-IAT ach-aff: performance on critical block 5 versus performance on critical block 2} \\
\hline \multicolumn{7}{|c|}{ Calculation of Absolute SPA-IAT measures } \\
\hline \multicolumn{7}{|c|}{$\mathrm{SPA}^{-\mathrm{IAT}_{\text {pow }}}=\left(\mathrm{SPA}-\mathrm{IAT}_{\text {pow-ach }}+\mathrm{SPA}-\mathrm{IAT}_{\text {pow-aff }}\right) / 2$} \\
\hline \multicolumn{7}{|c|}{ 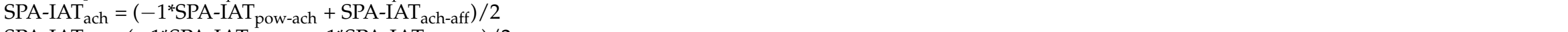 } \\
\hline SPA-IAT $\mathrm{aff}=\left(-1^{* \mathrm{~S}}\right.$ & ch-aff $-1 *$ SPA-I & & & & & \\
\hline
\end{tabular}


The first block of the SPA-IAT involves practice exercises to get participants acquainted with the task instructions. The remaining six blocks include substantive measurement tasks. These blocks are presented in a random order, and are used to construct the SPA-IAT scores. Each implicit motive is part of two substantive blocks composed of 20 trials. In each trial, participants focus simultaneously on two labels that are plotted one under the other in the top center of the computer screen. One label represents the focal concept (for example, "power") and the other label the focal attribute (for example, "attractive"). Below these labels, a stimulus that either does or does not reflect the focal concept or attribute is presented in the center of the screen, and participants are instructed to press as quickly as possible the " $\mathrm{i}$ " key when the stimulus represents the focal categories, and to press the " $\mathrm{e}$ " key when the stimulus does not represent the focal categories. Relative SPA-IAT scores are derived from the comparison of participants' performance in two blocks that present the same focal attribute (for example, "attractive"), but with two different focal concepts (for example, "affiliation" and "power").

This procedure provides three SPA-IAT scores: The power (pow) relative to the achievement (ach) motive, the power relative to the affiliation (aff) motive, and the achievement relative to the affiliation motive. We computed the SPA-IAT scores with data from all substantive blocks following the scoring recommendations of Nosek et al. [87]. We estimated internal consistency of the SPA-IATs by splitting each substantive block into two sub-blocks of equal length. The first sub-block contained the even trials and the second the odd trials. SPA-IAT scores were computed for each sub-block separately. We found a good split-half reliability for all three SPA-IATs (Spearman-Brown coefficients SPA-IAT pow-ach: 0.79; SPA-IAT pow-aff: 0.77; SPA-IAT ach-aff: 0.78). Because we are interested in the effect of a dominant implicit power motive, we averaged the power relative to the achievement motive score (SPA-IAT pow-ach) and the power relative to the affiliation motive score (SPA-IAT pow-aff) to obtain a single implicit power score (SPA-IAT pow). This approach is comparable with the TAT and PSE motive measures, as these measures present participants with a series of ambiguous pictures, each eliciting multiple motives at a time.

\subsubsection{Dependent Variables}

Brief and Motowidlo ([9], p. 711) define prosocial organizational behavior as "behavior which is (a) performed by a member of an organization, (b) directed toward an individual, group, or organization with whom he or she interacts while carrying out his or her organizational role, and (c) performed with the intention of promoting the welfare of the individual, group, or organization toward which it is directed." To address the heterogeneity of this construct [61], two options are possible. First, one can rely on a formative scale to measure prosocial goals in SMEs and explore the impact of motives through a structural equation model. This option is more demanding in terms of sample size than the second option, which involves using separate single-item constructs or reflective scales while focusing on one or a couple of the sub-dimensions of prosocial behavior in separate analyses, one for each sub-dimension. Given the exploratory nature of the current paper, we opted for the second option, and examined the impact of the power motives on two crucial SME-related prosocial dimensions in parallel.

More specifically, we selected job creation and taking care of the environment as two relevant prosocial goals for SMEs' key decision-makers, and performed a series of OLS regressions on both goals separately. By doing so, we explicitly acknowledge that, even though prosocial behavior has the central notion of benefiting others [9], this is a broad and multi-dimensional concept that deserves an in-depth analysis of each dimension separately. Job creation is a widely accepted prosocial outcome, adding value to society [89]. Job creation is the engine of social and economic development, with small businesses argued to be an important engine of such social benefits [12]. Taking care of the environment is another prominent manifestation of prosocial behavior linked to business activities, to the benefit of a wide variety of stakeholders [89]. More specifically, in Yunus et al. [90], the social profit equation explicitly includes environmental (that is, ecological) "profit". Likewise, Porter and Kramer [1] argue that environmental (green) performance should be a central aspect of shared value creation. More 
recently, the importance of environmental sustainability is included in the Community Impact subscale, as a central dimension of entrepreneurial success [91].

In line with recent work on human motives, we relied on self-reported single-item measures of the outcome variables. According to Steinmann et al. [92], the use of single-item measures as dependent variables in research on motives is appropriate when three main conditions are met: (1) the construct of interest is sufficiently narrow, with (2) one main dimension that (3) is straightforward to the participants. This is in line with Wanous and Hudy [93] who suggest that when a construct has multiple dimensions, each dimension may be measured with a single item on the condition that the latter is reliable. Bergkvist and Rossiter [94] provide empirical evidence regarding the validity of single-item measures, showing that such items are valid if respondents consider the construct as "concrete" and "easily and uniformly imagined". Indeed, job creation and taking care of the environment are unidimensional and straightforward from an entrepreneurial perspective. For example, the well-established and oft-used Global Entrepreneurship Monitoring surveys yearly incorporate a list of single items, including individuals' concerns for the environment within their business or within their entrepreneurial project.

In the current study, the respondents from the 2012 survey were asked to indicate the importance attached to "job creation" and "taking care of the environment" on a seven-point Likert scale, ranging from "very unimportant" to "very important". To assure that these items were reliable [93], appropriate [92], and valid [94], we conducted a series of pilot interviews during questionnaire development, and adopted careful backward translation procedures from Dutch to French and vice versa. Through such a pretesting phase, we could explicitly pay attention to wording, reducing item ambiguity [95]. As a robustness check, we ran all models reported below for both language sub-samples separately, producing results that were completely sign-consistent (results available upon request). Given all this, we can safely conclude that our single-item measures are valid, reliable and appropriate.

\subsubsection{Control Variables}

In his review of the work on entrepreneurs' motives, Johnson [34] recommends considering the individual, the venture and the social context as classes of potential factors influencing the relationship between motives and any dependent variable. We include control variables that account for all three of Johnson's [34] classes of critical factors.

At the individual level, we first control for gender, age and education level, three basic demographics that have been used in prior work on prosocial behavior in SMEs and start-up enterprises [96]. Second, we control for the percentage owned by our key decision-makers in their business, as the degree of commitment of the decision-makers can influence prosocial organizational behavior [97]. As any ownership minimum threshold cannot be but arbitrary, we control for the percentage of shares owned by our key decision-makers.

Finally, we also add measures of explicit achievement and explicit affiliation motives, both being argued to be relevant self-reported motives [37]. Especially, the explicit achievement motive has been identified as a driver of social entrepreneurship [21], expected to be positively associated with prosocial behavior.

At the venture level, we include the size of the business, measured as the number of full-time equivalents [range between 1 and 136]. Indeed, firm size has been used in other studies on social responsibility in SMEs, albeit with contrasting results [12].

Proxies for the social context are included in terms of business sector and cultural differences. As proposed by De Clerq and Voronov [98], decision-makers might be influenced by the field-prescribed balance between sustainability and profitability. As a result, prosocial behavior may have a different level of legitimacy in different business sectors and cultures. We add dummies for manufacturing and agriculture, taking services (including trade and transport) as the referential category. To account for cultural differences, which have been related to both small businesses [99] and motives [100], we include the mother tongue of the respondent (French-speaking = 0; Dutch-speaking = 1). In Belgium, 
the two largest regions are the Dutch-speaking region of Flanders in the North and the French-speaking region of Wallonia in the South (including Brussels). This dummy captures differences in formal institutions such as the regional legal framework, as well as informal institutions such as habits and traditions. This might be especially important since the literature on CSR highlights how different institutional contexts can have an impact on the voluntary and deliberate commitment of firms to CSR issues, such as job creation and the protection of the environment [18].

\section{Results}

A series of OLS regression analyses was conducted with the prosocial goals taking care of the environment and job creation as the dependent variables, using a heteroscedasticity-consistent standard error estimator (HC3). We entered the control variables into the first block (Models 1a and $1 \mathrm{~b}$, regressed on taking care of the environment and job creation, respectively), the explanatory variables into the second block (Model $2 \mathrm{a}$ and $2 \mathrm{~b}$, regressed on taking care of the environment and job creation, respectively), and the interaction term into the third block (Model 3a and 3b, regressed on taking care of the environment and job creation, respectively). Explicit-implicit congruence was tested by entering a product term between the corresponding explicit and implicit motive scores [100]. Descriptive statistics are provided in Table 3, and the estimates are reported in Table 4. To determine the merits of adding additional parameters and interaction terms to the models, we calculated the change in adjusted R-squared and assessed its significance using an F-test. Significant changes in adjusted R-squared revealed that adding our explanatory variables (Models 2a, 2b), as well as the interaction terms (Models 3a, 3b) provided better model fit for both prosocial goals (see Table 3).

Because main effects cannot be interpreted directly in a model with significant interaction effects [101], we only rely on Models $2 a$ and $2 b$ to test our main effect Hypotheses. Hypothesis 1 posits that key decision-makers with a dominant implicit power motive attach more importance to their SME's prosocial goals than do their counterparts motivated differently. Supporting evidence is found for job creation (Coeff. $=0.93 ; \mathrm{SE}=0.40 ; p=0.021$ ), but not for taking care of the environment. It suggests that, in general, implicit power is positively associated with the importance attached to job creation. According to Hypothesis 2, key decision-makers scoring higher on the explicit power motive attach less importance to their SME's prosocial goals. The results reveal that explicit power is significant in neither Model 2a nor Model 2b. Hence, we do not find support for Hypothesis 2.

However, we find significant and negative interactions between explicit and implicit power motives for both taking care of the environment (Coeff. $=-1.39 ; \mathrm{SE}=0.49 ; p=0.006$ ) and job creation (Coeff. $=-1.42 ; \mathrm{SE}=0.71 ; p=0.049$ ), suggesting that the positive effect of the implicit power motive is neutralized when the SME's key decision-maker scores high on explicit power. This provides preliminary support for Hypothesis 3. More importantly, this finding qualifies the results for the main-effect Hypotheses 1 and 2, as the effects are conditional on the different levels of the moderator. We examine the conditional effect in greater detail below.

To clarify these results, we first plotted the interactions in Figures 1 and 2, following the "pick-a-point" approach of Rogosa [102], and performed a simple slope analysis to qualify the slopes of the interaction in Tables 5 and 6 [103]. 
Table 3. Descriptive data and correlation table.

\begin{tabular}{|c|c|c|c|c|c|c|c|c|c|c|c|c|c|c|c|c|c|c|}
\hline & & Min & $\operatorname{Max}$ & Mean & SD & 1 & 2 & 3 & 4 & 5 & 6 & 7 & 8 & 9 & 10 & 11 & 12 & 13 \\
\hline 1 & $\begin{array}{l}\text { Taking care of the } \\
\text { environment }\end{array}$ & -2.00 & 3.00 & 1.44 & 1.31 & 1.00 & & & & & & & & & & & & \\
\hline 2 & Job Creation & -3 & 3 & 0.88 & 1.75 & $0.43^{* * *}$ & 1.00 & & & & & & & & & & & \\
\hline 3 & Manufacturing & 0.00 & 1.00 & 0.13 & 0.34 & 0.16 & 0.06 & 1.00 & & & & & & & & & & \\
\hline 4 & Agriculture & 0.00 & 1.00 & 0.01 & 0.10 & 0.12 & 0.06 & -0.04 & 1.00 & & & & & & & & & \\
\hline 5 & Business size & 1.00 & 136 & 10.37 & 19.75 & 0.00 & $0.25^{* *}$ & -0.07 & -0.03 & 1.00 & & & & & & & & \\
\hline 6 & Ownership & 0.00 & 1.00 & 0.76 & 0.35 & 0.00 & $-0.241 *$ & -0.03 & 0.06 & $-0.38^{* *}$ & 1.00 & & & & & & & \\
\hline 7 & Gender & 1.00 & 2.00 & 1.27 & 0.45 & -0.13 & -0.11 & 0.08 & -0.06 & -0.13 & 0.11 & 1.00 & & & & & & \\
\hline 8 & Culture & 0.00 & 1.00 & 0.47 & 0.50 & -0.08 & -0.04 & 0.19 & 0.10 & 0.10 & -0.08 & -0.03 & 1.00 & & & & & \\
\hline 9 & Level of education & 1.00 & 2.00 & 1.82 & 0.38 & -0.10 & -0.00 & -0.04 & 0.04 & 0.06 & -0.02 & 0.06 & -0.10 & 1.00 & & & & \\
\hline 10 & Age & 26.00 & 70.00 & 47.44 & 8.65 & 0.05 & -0.13 & -0.03 & -0.05 & -0.06 & 0.06 & -0.15 & 0.15 & 0.07 & 1.00 & & & \\
\hline 11 & Explicit affiliation & 1.12 & 4.69 & 3.34 & 0.61 & $0.19 *$ & 0.16 & 0.033 & -0.01 & 0.02 & 0.02 & 0.08 & 0.08 & -0.04 & 0.04 & 1.00 & & \\
\hline 12 & $\begin{array}{c}\text { Explicit } \\
\text { achievement }\end{array}$ & 2.44 & 4.94 & 3.8 & 0.49 & $0.24 *$ & $0.23 *$ & 0.04 & -0.11 & $0.22 *$ & -0.21 * & -0.04 & 0.10 & 0.02 & 0.18 & $0.31 * *$ & 1.00 & \\
\hline 13 & Explicit power & 2.31 & 4.81 & 3.49 & 0.50 & 0.03 & $0.21 *$ & -0.09 & -0.13 & $0.37 * *$ & $-0.21 *$ & $-0.23 *$ & 0.01 & 0.11 & 0.15 & $0.20^{*}$ & $0.52 * *$ & 1.00 \\
\hline 14 & Implicit power & -1.69 & 0.74 & -0.47 & 0.45 & 0.01 & 0.18 & 0.06 & 0.00 & 0.09 & -0.05 & -0.01 & -0.12 & 0.16 & -0.04 & $-0.29 * *$ & -0.19 & -0.03 \\
\hline
\end{tabular}

Note: SD = Standard Deviation. Taking care of the environment and job creation are measured on a seven-point Likert-scale from -3 ("Not at all important") to 3 ("Very important"). Sectors have two categories [0; 1]. Business Size is the number of full-time equivalents. Ownership is the percentage of the business owned by the respondent. Gender has two categories: $1=$ male; $2=$ female. Culture is indicated by the mother tongue of the respondent: $0=$ French-speaking; $1=$ Dutch-speaking. Level of education has two categories: $1=$ no higher education;
$2=$ with a higher education degree. Explicit motives are measured on a five-point Likert-scale from 1 ("Does not fit at all") to 5 ("Fits very well"). Implicit power is a latency-based score computed based on the recommendations of Nosek et al. [87]. Two-tail correlation test: ${ }^{*} p<0.05 ;{ }^{* *} p<0.01$; ${ }^{* *} p<0.001$. Sample size $n=108$. 
Table 4. Heteroscedasticity-consistent standard error estimates for the OLS regressions on the prosocial organizational goals taking care of the environment and job creation.

\begin{tabular}{|c|c|c|c|c|c|c|c|c|c|c|c|c|c|c|c|c|c|c|}
\hline \multirow{4}{*}{$\begin{array}{c}\text { Parameters } \\
\text { Constant }\end{array}$} & \multicolumn{13}{|c|}{ OLS Regressions on Taking Care of the Environment } & \multicolumn{5}{|c|}{ OLS Regressions on Job Creation } \\
\hline & \multicolumn{3}{|c|}{ Model 1a } & \multicolumn{3}{|c|}{ Model 2a } & \multicolumn{3}{|c|}{ Model 3a } & \multicolumn{3}{|c|}{ Model 1b } & \multicolumn{3}{|c|}{ Model 2b } & \multicolumn{3}{|c|}{ Model 3b } \\
\hline & Coef & (SE) & $p$ & Coef & (SE) & $p$ & Coef & $(\mathrm{SE})$ & $p$ & Coef & (SE) & $p$ & Coef & (SE) & $p$ & Coef & (SE) & $p$ \\
\hline & -0.78 & & 0.618 & -0.27 & 1.77 & 0.877 & 2.20 & 1.86 & 0.238 & -0.13 & 1.78 & 0.942 & -0.55 & 1.96 & 0.780 & 1.99 & & 0.414 \\
\hline \multicolumn{19}{|l|}{ Control variables } \\
\hline Business sectors ${ }^{1}$ & 0.86 & 0.30 & $0.006^{* *}$ & 0.77 & 0.31 & $0.014 *$ & 0.92 & 0.31 & $0.004 * *$ & 0.49 & 0.47 & 0.293 & 0.38 & 0.44 & 0.390 & 0.54 & 0.44 & 0.218 \\
\hline Business size & 0.00 & 0.01 & 0.901 & 0.00 & 0.01 & 0.960 & 0.00 & 0.01 & 0.813 & 0.01 & 0.02 & 0.391 & 0.01 & 0.02 & 0.547 & 0.01 & 0.02 & 0.439 \\
\hline Ownership & 0.00 & 0.00 & 0.729 & 0.00 & 0.00 & 0.720 & 0.00 & 0.00 & 0.790 & -0.01 & 0.00 & 0.146 & -0.01 & 0.00 & 0.179 & -0.01 & 0.00 & 0.137 \\
\hline Gender & -0.43 & 0.31 & 0.177 & -0.51 & 0.31 & 0.103 & -0.40 & 0.31 & 0.206 & -0.44 & 0.39 & 0.255 & -0.44 & 0.39 & 0.264 & -0.32 & 0.40 & 0.420 \\
\hline Culture & -0.46 & 0.28 & 0.112 & -0.45 & 0.29 & 0.131 & -0.48 & 0.28 & $0.090^{\top}$ & -0.34 & 0.38 & 0.375 & -0.24 & 0.39 & 0.540 & -0.27 & 0.38 & 0.488 \\
\hline Level of education & -0.36 & 0.31 & 0.256 & -0.35 & 0.32 & 0.280 & -0.40 & 0.31 & 0.210 & -0.02 & 0.52 & 0.972 & -0.17 & 0.47 & 0.717 & -0.22 & 0.46 & 0.640 \\
\hline Age & 0.00 & 0.02 & 0.874 & 0.00 & 0.02 & 0.828 & 0.00 & 0.02 & 0.854 & -0.03 & 0.02 & 0.164 & -0.03 & 0.02 & 0.156 & -0.03 & 0.02 & 0.137 \\
\hline Explicit affiliation & 0.30 & 0.21 & 0.159 & 0.37 & 0.22 & $0.090^{\top}$ & 0.31 & 0.23 & 0.176 & 0.37 & 0.27 & 0.172 & 0.52 & 0.29 & $0.080^{\top}$ & 0.46 & 0.30 & 0.138 \\
\hline $\begin{array}{c}\text { Explicit } \\
\text { achievement }\end{array}$ & 0.59 & 0.30 & $0.049^{*}$ & 0.80 & 0.33 & $0.015^{*}$ & 0.79 & 0.30 & $0.009^{* *}$ & 0.57 & 0.34 & $0.090^{\top}$ & 0.66 & 0.42 & 0.124 & 0.64 & 0.41 & 0.123 \\
\hline \multicolumn{19}{|c|}{ Main and conditional effects } \\
\hline Explicit power & & & & -0.41 & 0.41 & 0.326 & -1.04 & 0.45 & $0.023 *$ & & & & 0.09 & 0.44 & 0.84 & -0.56 & 0.49 & 0.256 \\
\hline Implicit power & & & & 0.28 & 0.28 & 0.325 & 5.15 & 1.75 & $0.004^{* *}$ & & & & 0.93 & 0.40 & $0.021 *$ & 5.91 & 2.56 & $0.023 *$ \\
\hline $\begin{array}{c}\text { Implicit * Explicit } \\
\text { power }\end{array}$ & & & & & & & -1.39 & 0.49 & $0.006^{* *}$ & & & & & & & -1.42 & 0.71 & $0.049 *$ \\
\hline \multicolumn{19}{|l|}{ Model Fit } \\
\hline $\mathrm{F}$ & 2.81 & & $0.006^{* *}$ & 3.06 & & $0.001^{* *}$ & 4.10 & & 0.000 & 2.33 & & $0.02 *$ & 2.58 & & $0.006^{* *}$ & 2.78 & & $0.003^{* *}$ \\
\hline $\begin{array}{l}\text { Adjusted } \\
\text { R-squared }\end{array}$ & 0.17 & & & 0.19 & & & 0.24 & & & 0.17 & & & 0.22 & & & 0.25 & & \\
\hline $\begin{array}{l}\text { Change in adj. } \\
\text { R-squared }\end{array}$ & & & & 0.02 & & & 0.05 & & & & & & 0.05 & & & 0.03 & & \\
\hline
\end{tabular}

${ }^{1}$ Due to the small number of observations related to the agriculture sector, and for the sake of parsimony, the dummies for Agriculture and Manufacturing have been merged; ${ }^{\top} p<0.1$; ${ }^{*} p<0.05$; ** $p<0.01$; ${ }^{* * *} p<0.001$. 


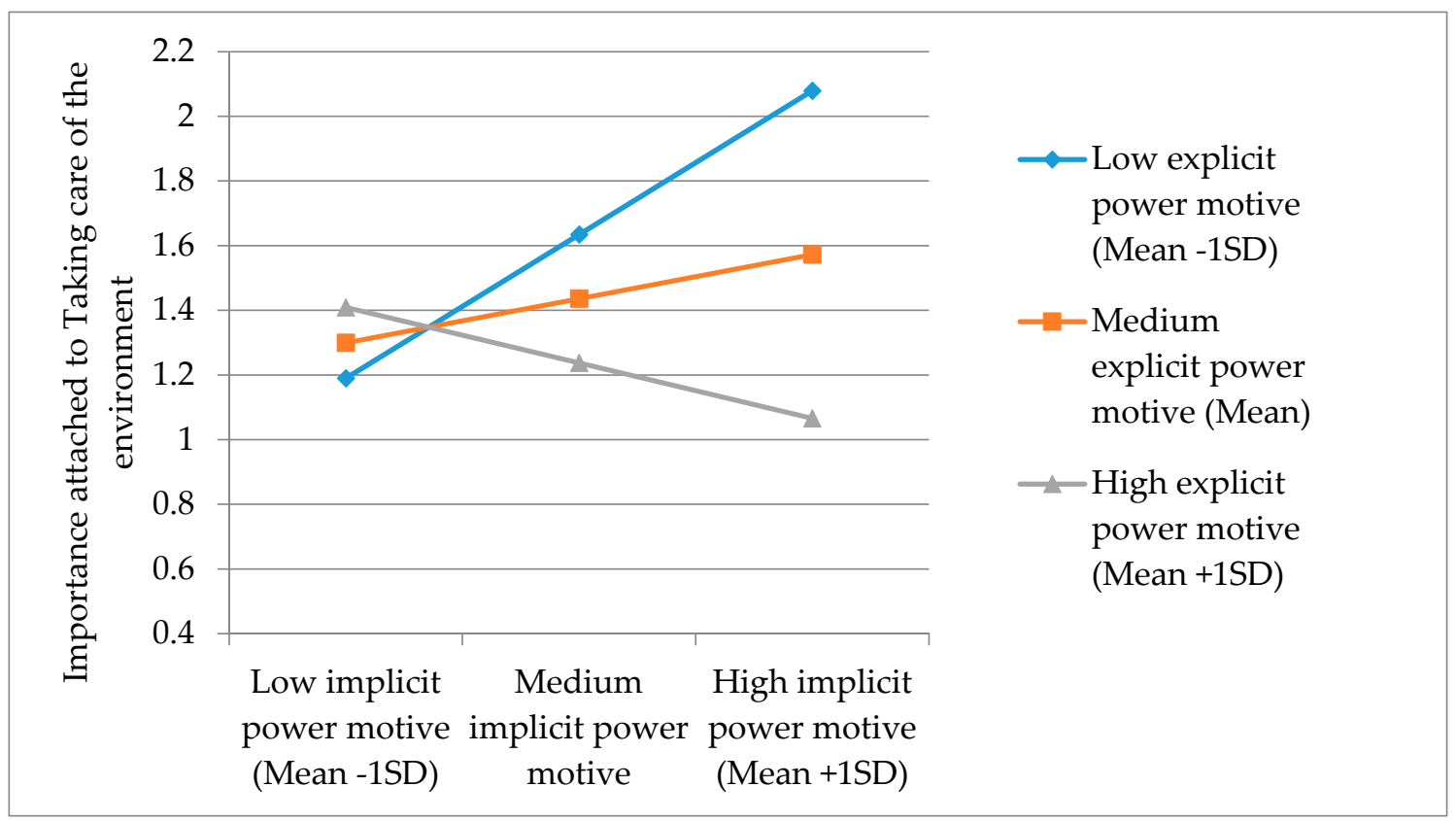

Figure 1. Conditional effect of the implicit power motive on the importance attached to taking care of the environment, at low (mean - 1SD), medium (mean) and high (mean + 1SD) levels of the moderator, explicit power motive.

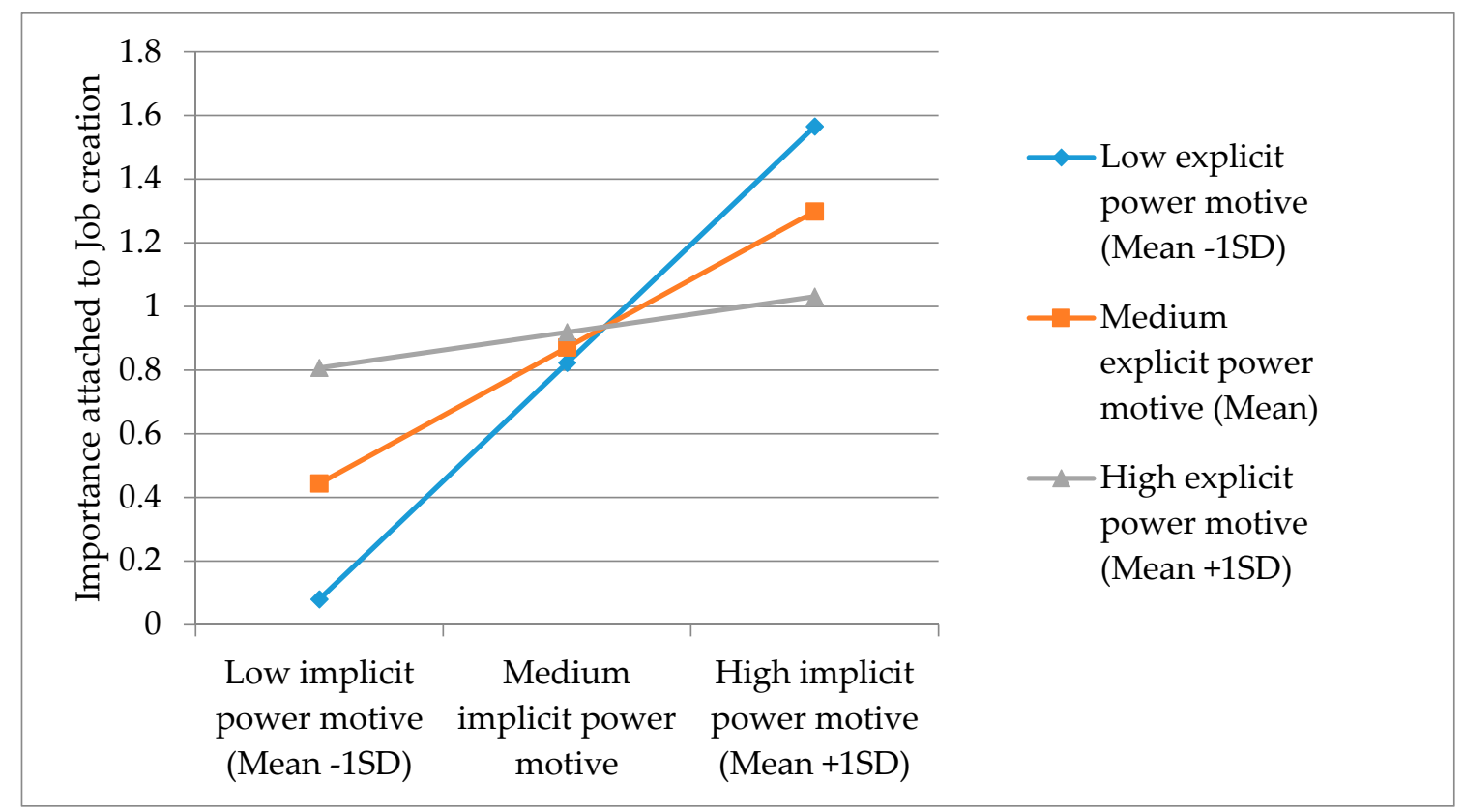

Figure 2. Conditional effect of the implicit power motive on the importance attached to job creation, at low (mean - 1SD), medium (mean) and high (mean + 1SD) levels of the moderator, explicit power motive.

Figures 1 and 2, as well as the results in Tables 5 and 6, show that the relationship between the implicit power motive and the importance attached to prosocial goals is positive, strong and significant for people scoring low on the explicit power motive (Mean - 1SD). They also reveal that the relationship becomes weaker and no longer significant at higher levels of the moderator. When the explicit power motive is high (Mean $+1 \mathrm{SD}$ ), the slope of the regression is negative but not significant for taking care of the environment, and positive but weak and no longer significant for job creation. 
Table 5. Conditional effect of the implicit power motive on taking care of the environment, at values of the moderator.

\begin{tabular}{|c|c|c|c|c|c|c|}
\hline $\begin{array}{l}\text { Value Moderator } \\
\text { Explicit Power }{ }^{1}\end{array}$ & $\begin{array}{c}\text { Conditional Effect } \\
\text { Coefficient for Implicit } \\
\text { Power }{ }^{2}\end{array}$ & $\begin{array}{l}\text { Standard } \\
\text { Error }\end{array}$ & $t$-Value & $p$-Value & $\begin{array}{c}\text { Lower Limit } \\
\text { Confidence } \\
\text { Interval }^{3}\end{array}$ & $\begin{array}{c}\text { Upper Limi } \\
\text { Confidence } \\
\text { Interval }^{3}\end{array}$ \\
\hline 3.00 & $1.00^{* *}$ & 0.36 & 2.75 & 0.007 & 0.28 & 1.72 \\
\hline 3.49 & 0.31 & 0.26 & 1.17 & 0.246 & -0.21 & 0.83 \\
\hline 3.99 & -0.38 & 0.36 & -1.08 & 0.283 & -1.09 & 0.32 \\
\hline
\end{tabular}

Notes: ${ }^{* *} p<0.01 ;{ }^{1}$ Values for the moderator are the mean and plus/minus one SD from mean. Moderator values defining the Johnson-Neyman significance region are 3.32 and 4.54 on a five-point Likert scale $(3=$ neutral, $4=$ the statement fits me well, and $5=$ the statement fits me very well); ${ }^{2}$ Heteroskedasticity-robust coefficients; ${ }^{3} 95$ percent bootstrap confidence interval.

Table 6. Conditional effect of the implicit power motive on job creation, at values of the moderator.

\begin{tabular}{ccccccc}
\hline $\begin{array}{c}\text { Value Moderator } \\
\text { Explicit Power }\end{array}$ & $\begin{array}{c}\text { Conditional Effect } \\
\text { Coefficient for Implicit } \\
\text { Power }^{\mathbf{2}}\end{array}$ & $\begin{array}{c}\text { Standard } \\
\text { Error }\end{array}$ & $\boldsymbol{t}$-Value & $\boldsymbol{p}$-Value & $\begin{array}{c}\text { Lower Limit } \\
\text { Confidence } \\
\text { Interval }^{\mathbf{3}}\end{array}$ & $\begin{array}{c}\text { Upper Limit } \\
\text { Confidence }^{\text {Interval }}{ }^{\mathbf{3}}\end{array}$ \\
\hline 3.00 & $1.67^{* *}$ & 0.56 & 2.98 & 0.004 & 0.56 & 2.77 \\
3.49 & $0.96^{*}$ & 0.38 & 2.55 & 0.012 & 0.21 & 1.70 \\
3.99 & 0.25 & 0.47 & 0.54 & 0.592 & -0.68 & 1.18 \\
\hline
\end{tabular}

Notes: ${ }^{* *} p<0.01 ;{ }^{*} p<0.05 ;{ }^{1}$ Values for the moderator are the mean and plus/minus one SD from mean. Moderator value defining the Johnson-Neyman significance region is 3.65 on a five-point Likert scale $(3=$ neutral, $4=$ the statement fits me well, and $5=$ the statement fits me very well); ${ }^{2}$ Heteroskedasticity-robust coefficients; ${ }^{3} 95$ percent bootstrap confidence interval.

We further examine the interactions by performing two Johnson-Neyman procedures via the PROCESS macro [104] in SPSS. This is a bootstrapping technique that estimates the conditional effect of the implicit power motive for all levels of the moderator and identifies regions of significance, which indicate over what range of the moderator the effect of the explanatory variable is significantly positive, non-significant, or significantly negative. For taking care of the environment, there are two regions of significance: below 3.32 and above 4.54. More specifically, the conditional effect of the implicit power motive on taking care of the environment is significantly positive when the value of the self-reported power motive is lower than 3.32 on a five-point Likert scale ( $3=$ neutral, $4=$ the statement fits me well, and $5=$ the statement fits me very well). When explicit power is higher than 3.32 but lower than 4.54, the conditional effect is no longer significant, implying that the implicit impulse is neutralized, as expected by Hypothesis 3. Interestingly, the effect becomes significantly negative when explicit power is higher than 4.54 on a five-point Likert scale, suggesting that, at very high levels of the moderator, the implicit impulse switches from positive to negative. For job creation, we found one region of significance: below 3.65 on a five-point Likert scale. When the explicit power disposition is below 3.65, implicit power positively influences the importance attached to job creation. When the explicit power disposition is higher than 3.65 , the implicit impulse is neutralized.

\section{Discussion}

Because explicit and implicit motives operate independently, they are not necessarily aligned and may generate different attitudinal or behavioral effects. In fact, recent contributions [52] show that their independence holds even when commensurable measures of implicit and explicit motives are used. This means that implicit measures often contradict self-reported ones [105]. In particular, implicit and explicit motives can conflict with each other-a central proposition of the dual system approach to motivation [51], and a central argument in the current study.

Our results suggest a conditional positive effect of the key decision-makers' implicit power motive on prosocial goals in their SMEs, in terms of job creation and taking care of the environment, if their explicit power motive is low. Contrary to our expectations, we did not find support for a negative main effect of explicit power on job creation and taking care of the environment. However, 
we do find that the explicit power motive acts as a moderator of the relationship between implicit power and the importance attached to prosocial goals, both for job creation and for taking care of the environment. This is in line with Perugini and Prestwich's [81] "gatekeeper" model, where explicit motives are conceptualized as channeling, (re)routing implicit impulses. It also aligns with Kehr's [37] conceptual model, as well as recent empirical work, where conflicts between implicit and explicit motives are expected to impede intrinsic motivation [38,106] and goal attainment [36]. While in human motivation research, the importance of incongruent systems that may lead to ineffective behavior and performance deficits has been examined [107], this has largely been ignored in entrepreneurship and small business research.

In the current study, we provide a first exploration of Kehr's [37] hypothesis in a small business setting. More specifically, the importance attached to prosocial goals is positively associated with the implicit power motive provided that the SME's key decision-maker is not consciously power-oriented. Decision-makers who are explicitly and implicitly motivated by power may avoid focusing on prosocial goals, even if this means missing out on the intrinsic enjoyment of having impact on the broader environment of one's own business. Furthermore, the negative region of significance for implicit power on taking care of the environment and the lack of such a relation for job creation may suggest that explicit power has a relatively larger negative impact on environmental concerns than on job creation. Indeed, environmental concern could be a costlier signal [80] than the creation of jobs. This is also in line with Bashir et al. [108], who find that environmental activism is often associated with strong negative stereotypes. Further research is certainly needed to gain a better understanding of this result.

By conceptually and methodically separating implicit and explicit power motives, we were able to show their specific and combined effects on prosocial organizational goals. We also bring light to the conflicting results from the literature on power, and its ambiguous impact on prosocial behaviors. This would not have been possible without the availability of an efficient measure of implicit motives. Thus far, researchers had to rely on cumbersome and time-consuming measurement procedures for the assessment of implicit motives, which are not well-suited for business research [50,68]. In the current study, we build on the progress made in modern psychology to measure explicit and implicit motives adequately, reliably and validly [24,52]. We provide the first application of the SPA-IAT for motives in a business setting. Our research shows that the (SPA)-IAT is an advantageous and promising alternative for the assessment of implicit motives, which may stimulate further research on implicit processes in business settings.

Of course, future research is needed to overcome the limitations of our study. First, an important feature of the IAT scores is their relative nature. IATs provide association-based measures, assessing the relative strength of a target object compared with a carefully selected counter-category (for instance, Coke vs. Pepsi, and Power vs. Affiliation and/or Achievement). In this paper, we explore the effect of a dominant power motive relatively to affiliation and achievement. With this relative measure, we follow human motivation researchers, such as McClelland and Burnham [39], Sheldon et al. [71], and Winter and Stewart [64], who also examined the effect of dominant implicit motives. In addition, the traditional implicit motives measurement methods such as the TAT or PSE also use pictorial stimuli triggering impulses from one specific motive, in relation to the other motives. However, this approach has one important downside: As we decided to measure implicit power motive as a relative measure, its significant impact on prosocial goals might hide the influence of a dominant affiliation or achievement motive instead. To address this concern, we ran additional robustness checks where we added either implicit achievement or affiliation motives as control variables. This robustness check yielded similar results as our original model, with a significant conditional effect of implicit power motives on job creation and taking care of the environment. More importantly, the coefficients for both implicit achievement motive and implicit affiliation motive were non-significant.

Beyond the relative nature of the IAT, other limitations have to be acknowledged. First, our findings cannot be anything but tentative, given the relatively small sample size. Second, our sample 
cannot be considered as representative of the Belgian population of entrepreneurs, as significantly more women, self-employed and French-speaking entrepreneurs attended our workshops as compared to their shares in the Belgian population of entrepreneurs. A third limitation concerns the level of analysis. Prosocial goals are considered as objects of motivation; they result from an individual's goal pursuits, which are motivated in terms of power. In line with the theories referenced earlier, prosocial goals are considered as an individual-level construct. More precisely, respondents are asked about the business goals that are important for them inside the SME, as key decision-makers. While this is relevant in small businesses in which organizational goals may largely reflect the drivers and preferences of the key decision-maker, our research falls short in examining actual behavior and priorities enacted upon in the firm. For that reason, we encourage further research to focus on the factors that facilitate (or limit) the translation of personal goals into discretionary prosocial practices [31]. Such studies might explain why Gadenne et al. [23] find a correlation between environmental awareness and green practices, while Mir and Feitelson [109] fail to find such a significant relationship. Based on our study's results, we suggest including implicit motivational factors as boundary conditions for the translation from awareness to agenda and action.

Another interesting venue for further development is the examination of entrepreneurial action and its regulation [110]. From this perspective, interesting work by Oertig et al. [111] already combines the study of human motives with self-determination theories. Examining the interaction with other self-regulation mechanism, such as perceived capabilities [37], may be very promising. This is especially relevant in entrepreneurship and small business research, which has long recognized self-regulation as a central micro-foundation. To continue in this direction, a process perspective is most promising, either through longitudinal surveys or experimental designs.

Finally, we would like to explicitly acknowledge that our focus on human motives does not deny the influence of the institutional context. As highlighted in the CSR literature [18], the erosion of regulated and mandatory CSR practices, such as those concerning wealth distribution or environmental protection, is giving firms more leeway to develop explicit-i.e., voluntary, deliberate and often strategic - CSR actions. An important research path would be to explore the articulation between the micro-level self-regulation mechanism central to this paper and the macro-level influence of the institutional context.

\section{Conclusions}

In this study, we argue that the lack of compelling empirical support to explain prosocial organizational behavior by human motives originates from the lack of management research about the (in)congruence between explicit and implicit motives. This study is a first attempt to better understand such a(n) (in)congruence effect of explicit and implicit power motives on the importance attached to prosocial goals in SMEs. Our results suggest that an implicit power motive is positively related to the importance that SMEs' key decision-makers attribute to the prosocial goals taking care of the environment and job creation. By contrast, we also provide evidence that an explicit power motive has a negative impact on prosocial goals. More specifically, we find that explicit power motives negatively moderate the implicit impulse on the prosocial goals job creation and taking care of the environment. By doing so, we shed light on the power paradox, and suggest that the importance attached to prosocial goals is positively associated with the implicit power motive provided that the SME's key decision-maker is not consciously power-oriented. When decision-makers are "pushed" toward prosocial goals by their implicit power motives, but "pulled" away from these goals by their explicit counterparts, they may avoid focusing on prosocial goals, even if this means missing out on the intrinsic enjoyment of actually influencing others.

Thus, we offer support for Kehr's [37] hypothesis that an implicit impulse can be neutralized by a conflicting conscious motive. As one of the first, we do so in a small business setting. This finding illustrates the importance of the conceptual and methodological differences between explicit and implicit motivational systems. Clearly, our study suggests that the full understanding of motivations 
can only be gained through the careful consideration of the interactions between implicit and explicit motives. We contribute to this endeavor by providing the SPA-IAT, an easy-to-use, rigorous alternative to the time-consuming projective methods and content analyses used in earlier studies. Building on the methodological progress in those research fields [50], we can continue the exploration of implicit constructs, as well as their interactions with their explicit counterparts.

A few practical implications may be derived from our study. First, we suggest that conflicting social norms might undermine the enjoyment associated with trying to change the world-for instance, through the diffusion of costly signals associated with altruistic behavior. Public policy might build on our results and work on reaching a positive relationship between explicit power and importance attributed to prosocial actions. For example, sensitization campaigns could frame prosocial behavior, especially environmental practices, as a status act (going green to be seen) [112]. They could also focus on an increase in moral identity as suggested, for example, by (as suggested by, for example, [77]), to mitigate the impeding effect of high explicit power. This relates to the responsibility of all members of society toward developing a discourse that embraces diversity in all its forms [113]. It also calls for a public discourse on prosocial goals that does not entrap individuals into a prescribed role within society [114]. Second, for entrepreneurs and key decision-makers themselves, we show that implicit motives matter. We claim that a better understanding of the interplay between implicit and explicit motives should shed light on the issue as to why people sometimes struggle to reach the goals they voluntarily and consciously set [37]. In particular, helping entrepreneurs gain awareness of the power paradox might help them manage internal tensions and embrace practices that are sources of intrinsic enjoyment. With such understanding, they can reach a better fit between their entrepreneurial project and their personal motives, which is likely to enhance both personal satisfaction and organizational performance.

Acknowledgments: This research has been carried out in the framework of the Belgian Science Policy Office research project TA $/ 00 / 40$, and was supported by the Interuniversity Attraction Pole "If not for profit, for what? And how?" funded by the Belgian Science Policy Office.

Author Contributions: The whole team participated in the conception, the design and performance of the experiments, and survey data collection. Hendrik Slabbinck, Julie Hermans and Johanna Vanderstraeten analyzed the data. Julie Hermans, Johanna Vanderstraeten, Hendrik Slabbinck, Arjen van Witteloostuijn and Marcus Dejardin wrote the paper.

Conflicts of Interest: The authors declare no conflict of interest.

\section{References}

1. Porter, M.E.; Kramer, M.R. The big idea: Creating shared value. Harv. Bus. Rev. 2011, 89, 2-17.

2. Szmigin, I.; Rutherford, R. Shared value and the impartial spectator test. J. Bus. Ethics 2013, 114, 171-182. [CrossRef]

3. Enderle, G. A rich concept of wealth creation beyond profit maximization and adding value. J. Bus. Ethics 2009, 84, 281-295. [CrossRef]

4. Cohen, B.; Smith, B.; Mitchell, R. Toward a sustainable conceptualization of dependent variables in entrepreneurship research. Bus. Strateg. Environ. 2008, 17, 107-119. [CrossRef]

5. Pruzan, P. The question of organizational consciousness: Can organizations have values, virtues and visions? J. Bus. Ethics 2001, 29, 271-284. [CrossRef]

6. Schumpeter, J.A. Change and the entrepreneur. In Essays of JA Schumpeter; Oxford University Press: London, UK, 1934.

7. Zahra, S.A.; Gedajlovic, E.; Neubaum, D.O.; Shulman, J.M. A typology of social entrepreneurs: Motives, search processes and ethical challenges. J. Bus. Ventur. 2009, 24, 519-532. [CrossRef]

8. Austin, J.; Stevenson, H.; Wei-Skillern, J. Social and commercial entrepreneurship: Same, different, or both? Entrep. Theory Pract. 2006, 30, 1-22. [CrossRef]

9. Brief, A.P.; Motowidlo, S.J. Prosocial organizational behaviors. Acad. Manag. Rev. 1986, 11, 710-725.

10. Shepherd, D.A. Party on! A call for entrepreneurship research that is more interactive, activity based, cognitively hot, compassionate, and prosocial. J. Bus. Ventur. 2015, 30, 489-507. [CrossRef] 
11. Spence, L.J.; Lozano, J.F. Communicating about ethics with small firms: Experiences from the uk and spain. J. Bus. Ethics 2000, 27, 43-53. [CrossRef]

12. Lepoutre, J.; Heene, A. Investigating the impact of firm size on small business social responsibility: A critical review. J. Bus. Ethics 2006, 67, 257-273. [CrossRef]

13. Markman, G.D.; Russo, M.; Lumpkin, G.T.; Jennings, P.D.; Mair, J. Entrepreneurship as a platform for pursuing multiple goals: A special issue on sustainability, ethics, and entrepreneurship. J. Manag. Stud. 2016, 53, 673-694. [CrossRef]

14. Jenkins, H. A 'business opportunity'model of corporate social responsibility for small-and medium-sized enterprises. Bus. Ethics Eur. Rev. 2009, 18, 21-36. [CrossRef]

15. Curran, J.; Rutherfoord, R.; Smith, S.L. Is there a local business community? Explaining the non-participation of small business in local economic development. Local Econ. 2000, 15, 128-143. [CrossRef]

16. Mickiewicz, T.; Sauka, A.; Stephan, U. On the compatibility of benevolence and self-interest: Philanthropy and entrepreneurial orientation. Int. Small Bus. J. 2016, 34, 303-328. [CrossRef]

17. Hiss, S. From implicit to explicit corporate social responsibility: Institutional change as a fight for myths. Bus. Ethics Q. 2009, 19, 433-451. [CrossRef]

18. Matten, D.; Moon, J. "Implicit" and "explicit" csr: A conceptual framework for a comparative understanding of corporate social responsibility. Acad. Manag. Rev. 2008, 33, 404-424. [CrossRef]

19. Schaper, M. Small firms and environmental management predictors of green purchasing in western australian pharmacies. Int. Small Bus. J. 2002, 20, 235-251. [CrossRef]

20. Shevchenko, A.; Lévesque, M.; Pagell, M. Why firms delay reaching true sustainability. J. Manag. Stud. 2016, 53, 911-935. [CrossRef]

21. Ruskin, J.; Seymour, R.G.; Webster, C.M. Why create value for others? An exploration of social entrepreneurial motives. J. Small Bus. Manag. 2016, 54, 1015-1037. [CrossRef]

22. Johnson, M.P.; Schaltegger, S. Two decades of sustainability management tools for smes: How far have we come? J. Small Bus. Manag. 2016, 54, 481-505. [CrossRef]

23. Gadenne, D.L.; Kennedy, J.; McKeiver, C. An empirical study of environmental awareness and practices in smes. J. Bus. Ethics 2009, 84, 45-63. [CrossRef]

24. Slabbinck, H.; De Houwer, J.; Van Kenhove, P. A pictorial attitude iat as a measure of implicit motives. Eur. J. Personal. 2011, 25, 76-86. [CrossRef]

25. Slabbinck, H.; De Houwer, J.; Van Kenhove, P. Convergent, discriminant, and incremental validity of the pictorial attitude implicit association test and the picture story exercise as measures of the implicit power motive. Eur. J. Personal. 2013, 27, 30-38. [CrossRef]

26. Nooteboom, B. Innovation and diffusion in small firms-Theory and evidence. Small Bus. Econ. 1994, 6, 327-347. [CrossRef]

27. Miller, D.; Toulouse, J.-M. Chief executive personality and corporate strategy and structure in small firms. Manag. Sci. 1986, 32, 1389-1409. [CrossRef]

28. Rauch, A.; Frese, M. Psychological approaches to entrepreneurial success: A general model and an overview of findings. Int. Rev. Ind. Organ. Psychol. 2000, 15, 101-142.

29. Baum, J.R.; Locke, E.A. The relationship of entrepreneurial traits, skill, and motivation to subsequent venture growth. J. Appl. Psychol. 2004, 89, 587-598. [CrossRef] [PubMed]

30. Del Baldo, M. Csr-oriented smes: A question of entrepreneurial virtues in action? Reflections in theory and practice. In Corporate Social Responsibility; Springer: Berlin, Germany, 2013; pp. 145-170.

31. Pinelli, M.; Maiolini, R. Strategies for sustainable development: Organizational motivations, stakeholders' expectations and sustainability agendas. Sustain. Dev. 2017, 25, 288-298. [CrossRef]

32. Gartner, W.B. Who is an entrepreneur? Is the wrong question. Am. J. Small Bus. 1988, 12, 11-32.

33. Collins, C.J.; Hanges, P.J.; Locke, E.A. The relationship of achievement motivation to entrepreneurial behavior: A meta-analysis. Hum. Perform. 2004, 17, 95-117. [CrossRef]

34. Johnson, B.R. Toward a multidimensional model of entrepreneurship: The case of achievement motivation and the entrepreneur. Entrep. Theory Pract. 1990, 14, 39-54.

35. Locke, E.A.; Latham, G.P. Building a practically useful theory of goal setting and task motivation: A 35-year odyssey. Am. Psychol. 2002, 57, 705-717. [CrossRef] [PubMed]

36. Brunstein, J.C.; Schultheiss, O.C.; Grässman, R. Personal goals and emotional well-being: The moderating role of motive dispositions. J. Personal. Soc. Psychol. 1998, 75, 494. [CrossRef] 
37. Kehr, H.M. Integrating implicit motives, explicit motives, and perceived abilities: The compensatory model of work motivation and volition. Acad. Manag. Rev. 2004, 29, 479-499.

38. Trapp, J.K.; Kehr, H.M. How the influence of the implicit power motive on negotiation performance can be neutralized by a conflicting explicit affiliation motive. Personal. Ind. Differ. 2016, 94, 159-162. [CrossRef]

39. McClelland, D.C.; Burnham, D.H. Power is the great motivator. Harv. Bus. Rev. 1976, 54, 100-110.

40. McClelland, D.C. Human Motivation; CUP Archive: Cambridge, UK, 1987.

41. McClelland, D.C.; Atkinson, J.; Clark, R.; Lowell, E. The Achievement Motive; Appleton-Century-Crofts: East Norwal, CT, USA, 1953; p. 384.

42. McClelland, D.C.; Watson, R.I. Power motivation and risk-taking behavior. J. Personal. 1973, 41, $121-139$. [CrossRef]

43. Winter, D.G. The Power Motive; The Free Press: New York, NY, USA, 1973.

44. Stewart, W.H.; Roth, P.L. A meta-analysis of achievement motivation differences between entrepreneurs and managers. J. Small Bus. Manag. 2007, 45, 401-421. [CrossRef]

45. Busenitz, L.W.; Barney, J.B. Differences between entrepreneurs and managers in large organizations: Biases and heuristics in strategic decision-making. J. Bus. Ventur. 1997, 12, 9-30. [CrossRef]

46. Frese, M.; Gielnik, M.M. The psychology of entrepreneurship. Annu. Rev. Organ. Psychol. Organ. Behav. 2014, 1, 413-438. [CrossRef]

47. Carsrud, A.; Brännback, M. Entrepreneurial motivations: What do we still need to know? J. Small Bus. Manag. 2011, 49, 9-26. [CrossRef]

48. Hansemark, O.C. Need for achievement, locus of control and the prediction of business start-ups: A longitudinal study. J. Econ. Psychol. 2003, 24, 301-319. [CrossRef]

49. Schuh, S.C.; Bark, A.S.H.; Van Quaquebeke, N.; Hossiep, R.; Frieg, P.; Van Dick, R. Gender differences in leadership role occupancy: The mediating role of power motivation. J. Bus. Ethics 2014, 120, 363-379. [CrossRef]

50. Uhlmann, E.L.; Leavitt, K.; Menges, J.I.; Koopman, J.; Howe, M.; Johnson, R.E. Getting explicit about the implicit: A taxonomy of implicit measures and guide for their use in organizational research. Organ. Res. Methods 2012, 15, 553-601. [CrossRef]

51. McClelland, D.C.; Koestner, R.; Weinberger, J. How do self-attributed and implicit motives differ. Psychol. Rev. 1989, 96, 690-702. [CrossRef]

52. Schultheiss, O.C.; Yankova, D.; Dirlikov, B.; Schad, D.J. Are implicit and explicit motive measures statistically independent? A fair and balanced test using the picture story exercise and a cue-and response-matched questionnaire measure. J. Personal. Assess. 2009, 91, 72-81. [CrossRef] [PubMed]

53. Bandura, A. Self-efficacy: Toward a unifying theory of behavioral change. Psychol. Rev. 1977, 84, 191-215. [CrossRef] [PubMed]

54. Baumann, N.; Kaschel, R.; Kuhl, J. Striving for unwanted goals: Stress-dependent discrepancies between explicit and implicit achievement motives reduce subjective well-being and increase psychosomatic symptoms. J. Personal. Soc. Psychol. 2005, 89, 781-799. [CrossRef] [PubMed]

55. Thrash, T.M.; Elliot, A.J. Implicit and self-attributed achievement motives: Concordance and predictive validity. J. Personal. 2002, 70, 729-756.

56. Baumann, N.; Chatterjee, M.B.; Hank, P. Guiding others for their own good: Action orientation is associated with prosocial enactment of the implicit power motive. Motiv. Emot. 2016, 40, 56-68. [CrossRef]

57. Winter, D.G.; Barenbaum, N.B. Responsibility and the power motive in women and men. J. Personal. 1985, 53, 335-355. [CrossRef]

58. Schultheiss, O.C.; Brunstein, J.C. Inhibited power motivation and persuasive communication: A lens model analysis. J. Personal. 2002, 70, 553-582.

59. Hofer, J.; Busch, H.; Chasiotis, A.; Kärtner, J.; Campos, D. Concern for generativity and its relation to implicit pro-social power motivation, generative goals, and satisfaction with life: A cross-cultural investigation. J. Personal. 2008, 76, 1-30. [CrossRef] [PubMed]

60. Kirkpatrick, S.A.; Wofford, J.; Baum, J.R. Measuring motive imagery contained in the vision statement. Leadersh. Q. 2002, 13, 139-150. [CrossRef]

61. Batson, C.D.; Powell, A.A. Altruism and prosocial behavior. In Handbook of Psychology. Volume 5: Personality and Social Psychology; Millon, T., Lerner, M.J., Weirner, I.B., Eds.; Wiley: Hoboken, NJ, USA, 2003; pp. $463-484$. 
62. Schultheiss, O.C.; Wirth, M.M.; Waugh, C.E.; Stanton, S.J.; Meier, E.A.; Reuter-Lorenz, P. Exploring the motivational brain: Effects of implicit power motivation on brain activation in response to facial expressions of emotion. Soc. Cogn. Affect. Neurosci. 2008, 3, 333-343. [CrossRef] [PubMed]

63. Deci, E.L.; Ryan, R.M. The"what" and" why" of goal pursuits: Human needs and the self-determination of behavior. Psychol. Inq. 2000, 11, 227-268. [CrossRef]

64. Winter, D.G.; Stewart, A. Power motivation. In Dimens. Personal; London, H., Exner, J., Eds.; Wiley: New York, NY, USA, 1978; pp. 391-447.

65. McClelland, D.C.; Boyatzis, R.E. Leadership motive pattern and long-term success in management. J. Appl. Psychol. 1982, 67, 737-743. [CrossRef]

66. Krug, S.; Kuhl, U. Die entwicklung von motivförderprogrammen. In Motivationspsychologie und Ihre Anwendung; Vollmeyer, R., Brunstein, J., Eds.; Kohlhammer: Stuttgart, Germany, 2005; pp. 167-186.

67. Magee, J.C.; Langner, C.A. How personalized and socialized power motivation facilitate antisocial and prosocial decision-making. J. Res. Personal. 2008, 42, 1547-1559. [CrossRef]

68. Kehr, H.M. Implicit/explicit motive discrepancies and volitional depletion among managers. Personal. Soc. Psychol. Bull. 2004, 30, 315-327. [CrossRef] [PubMed]

69. Suessenbach, F.; Moore, A.B. Individual differences in the explicit power motive predict "utilitarian" choices in moral dilemmas, especially when this choice is self-beneficial. Personal. Ind. Differ. 2015, 86, 297-302. [CrossRef]

70. Maner, J.K.; Mead, N.L. The essential tension between leadership and power: When leaders sacrifice group goals for the sake of self-interest. J. Personal. Soc. Psychol. 2010, 99, 482-497. [CrossRef] [PubMed]

71. Sheldon, K.M.; King, L.A.; Houser-Marko, L.; Osbaldiston, R.; Gunz, A. Comparing iat and tat measures of power versus intimacy motivation. Eur. J. Personal. 2007, 21, 263-280. [CrossRef]

72. Schultz, P.W.; Gouveia, V.V.; Cameron, L.D.; Tankha, G.; Schmuck, P.; Franek, M. Values and their relationship to environmental concern and conservation behavior. J. Cross-Cult. Psychol. 2005, 36, 457-475. [CrossRef]

73. Baslevent, C.; Kirmanoglu, H. Discerning self-interested behaviour in attitudes towards welfare state responsibilities across europe. Int. J. Soc. Welf. 2011, 20, 344-352. [CrossRef]

74. Boer, D.; Fischer, R. How and When Do Personal Values Guide Our Attitudes and Sociality? Explaining Cross-Cultural Variability in Attitude-Value Linkages. Psychol. Bull. 2013, 139, 1113-1147. [CrossRef] [PubMed]

75. Engeser, S.; Langens, T. Mapping explicit social motives of achievement, power, and affiliation onto the five-factor model of personality. Scand. J. Psychol. 2010, 51, 309-318. [CrossRef] [PubMed]

76. Keltner, D.; Gruenfeld, D.; Anderson, C. Power, approach, and inhibition. Psychol. Rev. 2003, 110, $265-284$. [CrossRef] [PubMed]

77. DeCelles, K.A.; DeRue, D.S.; Margolis, J.D.; Ceranic, T.L. Does power corrupt or enable? When and why power facilitates self-interested behavior. J. Appl. Psychol. 2012, 97, 681-689. [CrossRef] [PubMed]

78. Meglino, B.; Korsgaard, M. Considering rational selfinterest as a disposition: Organizational implications of other orientation. J. Appl. Psychol. 2004, 89, 946-959. [CrossRef] [PubMed]

79. Grafen, A. Sexual selection unhandicapped by the fischer process. J. Theor. Biol. 1990, 144, 473-516. [CrossRef]

80. Millet, K.; Dewitte, S. Altruistic behavior as a costly signal of general intelligence. J. Res. Personal. 2007, 41, 316-326. [CrossRef]

81. Perugini, M.; Prestwich, A. The gatekeeper: Individual differences are key in the chain from perception to behaviour. Eur. J. Personal. 2007, 21, 303-317. [CrossRef]

82. Podsakoff, P.M.; Organ, D.W. Self-reports in organizational research: Problems and prospects. J. Manag. 1986, 12, 531-544. [CrossRef]

83. Jackson, D.N. Personality Research Form Manual; Research Psychologists Press: Port Huron, MI, USA, 1984.

84. Greenwald, A.G.; McGhee, D.E.; Schwartz, J.L. Measuring individual differences in implicit cognition: The implicit association test. J. Personal. Soc. Psychol. 1998, 74, 1464-1480. [CrossRef]

85. Bar-Anan, Y.; Nosek, B.A. A comparative investigation of seven indirect attitude measures. Behav. Res. Methods 2014, 46, 668-688. [CrossRef] [PubMed]

86. Brunstein, J.C.; Schmitt, C.H. Assessing individual differences in achievement motivation with the implicit association test. J. Res. Personal. 2004, 38, 536-555. [CrossRef]

87. Nosek, B.; Bar-Anan, Y.; Sriram, N.; Greenwald, A. Understanding and using the brief implicit association test. PLoS ONE 2014, 9, 11093. [CrossRef] [PubMed] 
88. Teige-Mocigemba, S.; Klauer, K.C.; Rothermund, K. Minimizing method-specific variance in the iat: A single block iat. Eur. J. Psychol. Assess. 2008, 24, 237-245. [CrossRef]

89. Rey-Martí, A.; Ribeiro-Soriano, D.; Sánchez-García, J.L. Giving back to society: Job creation through social entrepreneurship. J. Bus. Res. 2016, 69, 2067-2072. [CrossRef]

90. Yunus, M.; Moingeon, B.; Lehmann-Ortega, L. Building social business models: Lessons from the grameen experience. Long Range Plan. 2010, 43, 308-325. [CrossRef]

91. Wach, D.; Stephan, U.; Gorgievski, M. More than money: Developing an integrative multi-factorial measure of entrepreneurial success. Int. Small Bus. J. 2016, 34, 1098-1121. [CrossRef]

92. Steinmann, B.; Dörr, S.L.; Schultheiss, O.C.; Maier, G.W. Implicit motives and leadership performance revisited: What constitutes the leadership motive pattern? Motiv. Emot. 2015, 39, 167-174. [CrossRef]

93. Wanous, J.P.; Hudy, M.J. Single-item reliability: A replication and extension. Organ. Res. Methods 2001, 4, 361-375. [CrossRef]

94. Bergkvist, L.; Rossiter, J.R. The predictive validity of multiple-item versus single-item measures of the same constructs. J. Mark. Res. 2007, 44, 175-184. [CrossRef]

95. Arend, R.J. Entrepreneurship and dynamic capabilities: How firm age and size affect the 'capability enhancement-SME performance' relationship. Small Bus. Econ. 2014, 42, 33-57. [CrossRef]

96. Hechavarría, D.M.; Terjesen, S.A.; Ingram, A.E.; Renko, M.; Justo, R.; Elam, A. Taking care of business: The impact of culture and gender on entrepreneurs' blended value creation goals. Small Bus. Econ. 2017, 48, 225-257. [CrossRef]

97. O'Reilly, C.A.; Chatman, J. Organizational commitment and psychological attachment: The effects of compliance, identification, and internalization on prosocial behavior. J. Appl. Psychol. 1986, 71, 492-499. [CrossRef]

98. De Clercq, D.; Voronov, M. Toward a practice perspective of entrepreneurship entrepreneurial legitimacy as habitus. Int. Small Bus. J. 2009, 27, 395-419. [CrossRef]

99. Thurik, R.; Dejardin, M. Entrepreneurship and culture. In Entrepreneurship in Context; van Gelderen, M., Masurel, E., Eds.; Routledge: London, UK, 2012; pp. 175-186.

100. Hofer, J.; Chasiotis, A.; Campos, D. Congruence between social values and implicit motives: Effects on life satisfaction across three cultures. Eur. J. Personal. 2006, 20, 305-324. [CrossRef]

101. Hair, J.; Black, B.; Babin, B.; Anderson, R.; Tatham, R. Multivariate Data Analysis; Pearson, Prentice Hall Inc.: Upper Saddle River, NJ, USA, 2005.

102. Rogosa, D. Comparing nonparallel regression lines. Psychol. Bull. 1980, 88, 307-321. [CrossRef]

103. Aiken, L.S.; West, S.G. Multiple Regression: Testing and Interpreting Interactions; Sage: Newbury Park, CA, USA, 1991.

104. Hayes, A.F. Process: A Versatile Computational Tool for Observed Variable Mediation, Moderation, and Conditional Process Modeling. Available online: http:/ / www.afhayes.com/public/process2012.pdf (accessed on 18 September 2017).

105. Nosek, B.A. Moderators of the relationship between implicit and explicit evaluation. J. Exp. Psychol. Gen. 2005, 134, 565. [CrossRef] [PubMed]

106. Rawolle, M.; Wallis, M.S.; Badham, R.; Kehr, H.M. No fit, no fun: The effect of motive incongruence on job burnout and the mediating role of intrinsic motivation. Personal. Ind. Differ. 2016, 89, 65-68. [CrossRef]

107. Schultheiss, O.C.; Patalakh, M.; Rawolle, M.; Liening, S.; MacInnes, J.J. Referential competence is associated with motivational congruence. J. Res. Personal. 2011, 45, 59-70. [CrossRef]

108. Bashir, N.Y.; Lockwood, P.; Chasteen, A.L.; Nadolny, D.; Noyes, I. The ironic impact of activists: Negative stereotypes reduce social change influence. Eur. J. Soc. Psychol. 2013, 43, 614-626. [CrossRef]

109. Mir, D.F.; Feitelson, E. Factors affecting environmental behavior in micro-enterprises laundry and motor vehicle repair firms in jerusalem. Int. Small Bus. J. 2007, 25, 383-415. [CrossRef]

110. Brockner, J.; Higgins, E.T.; Low, M.B. Regulatory focus theory and the entrepreneurial process. J. Bus. Ventur. 2004, 19, 203-220. [CrossRef]

111. Oertig, D.; Schüler, J.; Schnelle, J.; Brandstätter, V.; Roskes, M.; Elliot, A.J. Avoidance goal pursuit depletes self-regulatory resources. J. Personal. 2013, 81, 365-375. [CrossRef] [PubMed]

112. Griskevicius, V.; Tybur, J.M.; Van den Bergh, B. Going green to be seen: Status, reputation, and conspicuous conservation. J. Personal. Soc. Psychol. 2010, 98, 392-404. [CrossRef] [PubMed] 
113. Fergus, A.H.; Rowney, J.I. Sustainable development: Lost meaning and opportunity? J. Bus. Ethics 2005, 60, 17-27. [CrossRef]

114. Perren, L.; Jennings, P.L. Government discourses on entrepreneurship: Issues of legitimization, subjugation, and power. Entrep. Theory Pract. 2005, 29, 173-184. [CrossRef] 